\title{
Interior surface materials as sources of indoor hygiene defects
}

\author{
Ingrid Juhasova Senitkova ${ }^{1, *}$ \\ ${ }^{1}$ Institute of Technology and Business in České Budějovice, Department of Civil Engineering, \\ Okružní 517/10, 37001 České Budějovice Czech Republic
}

\begin{abstract}
The building design and material selection has to respect the environmental requirements of indoor air quality and indoor hygiene parameters. As the first stage of building design is the most important for final indoor air quality more and more by clear constructional architecture the benefit of environmental safety, good indoor air quality for health and productivity are dominant. Nowadays the interior surface materials have received greatest attention as sources of indoor air pollution. The major pollutants in indoor air are volatile organic compounds emitted from materials and building products. Volatile organic compounds, or VOCs, are among the most complex and troubling indoor air pollutants. Manufactured and synthesized products often release large quantities of VOCs, some of the compounds they release, such as benzene, styrene, formaldehyde, and toluene, may be irritating, toxic, or even carcinogenic. VOCs emitted can become attached to other surfaces in the space, especially fabrics, and then be re-emitted over time. The impact of interior surface materials on air quality and indoor hygiene is discussed within the paper. The building design concerning to heath of occupants and hygienic performance regime can be realized only by interdisciplinary team of professionals respecting the environmental building and indoor design.
\end{abstract}

\section{Introduction}

Buildings are designed to provide shelter from the outdoor elements and to provide a safe and healthy indoor environment at work and home. If a building fails, the results can be structural damage, poor indoor air quality, health complaints, high absenteeism, and poor worker productivity, damage to belongings and manufactured goods, and costly remediation. The indoor environment may influence the health, comfort and productivity of occupants in buildings. Comfort can be defined as that condition of mind which expresses satisfaction with the environment. Health and comfort in the built environment is a multidisciplinary issue involving various specialists who bring together expertise on health, comfort, air quality and environmental monitoring and control. Environmental quality of indoors is the conceptual system principle of architectural, constructional and environmental design development.

\footnotetext{
*Corresponding author: 14667@mail.vstecb.cz
} 
Environmental safety building is determined with mass and environs aspect. Mass aspect is determined by the system Building-Material-Subject and environs aspect is influenced by Building-Fluid-Subject system. Environmental factors are determined by operative perceived comfort and safety criteria of indoor physical, chemical and biological compounds. Sustainable building design is doubtless task of mass and energy flow reduction. The mass flow reductions mostly consist in material recovery. The problems with indoor air quality occur when energy flow reduction works together with changed material base composition and used services technology became dominant. There is no contradiction between indoor air quality and energy performance, but the more mass is changed the more energy flow is needed [1].

Growing attention is being paid to indoor environment as one of the main health and well-being factors. Indoor air quality problems may arise from one or more of the following causes: indoor environment - inadequate temperature, humidity, lighting; excessive noise, indoor air contaminants - chemicals, dusts molds, fungi, gases, vapors, odors and insufficient outdoor air.

Many of the materials used in buildings, either as interior materials or as furnishings, are the main sources of indoor air pollution in addition to those caused by humans and their activities and HVAC systems. The important source is the indoor surface materials of building itself, which in many cases can result in great amount of indoor volatile organic compounds (VOCs). It is especially building material finishes (floors, walls and ceilings) which are considered to have an important role also of perceived indoor air quality [2]. The research project is focused to indoor air sciences especially to perceived air quality observation focused on selected chemicals occurrence in public buildings have shown that mainly office buildings have high level of pollution related to interior materials [3].

Also hygiene problems may mainly develop as a result of emissions from sources inside the building such as emissions from building materials, furniture and equipment. Additionally lack of outdoor air for HVAC system and defective HVAC systems as well as the pollutants present in the outdoor air entering the building may also cause the indoor air quality problems.

\section{Nature and source of indoor chemicals}

Chemical contaminants of the indoor air can occur as gases and vapours (inorganic and organic) and particulates. Their presence in the indoor environment is the result of entry into the building from the outdoor environment or their generation within the building. The relative importance of these indoor and outdoor origins differs for different pollutants and may vary over time. The major chemical pollutants commonly found in the indoor air are the following: organic compounds, carbon dioxide, carbon monoxide, nitrogen oxides, sulphur dioxide and ozone.

Carbon dioxide $\left(\mathrm{CO}_{2}\right)$ is a metabolic product and often used as an indicator of the general level of air pollution related to the presence of humans indoors Carbon monoxide (CO), nitrogen oxides $\left(\mathrm{NO}_{\mathrm{x}}\right)$ and sulphur dioxide $\left(\mathrm{SO}_{2}\right)$ are inorganic combustion gases formed predominantly during the combustion of fuels and ozone $\left(\mathrm{O}_{3}\right)$, is a product of photochemical reactions in polluted atmospheres but may also be released by some indoor sources. Elevated levels of pollutants generated by combustion, particularly nitrogen dioxide and carbon monoxide in indoor spaces, usually result from unvented, improperly vented or poorly maintained combustion appliances and the smoking of tobacco products. Unvented kerosene and gas space heaters emit significant quantities of $\mathrm{CO}, \mathrm{CO}_{2}, \mathrm{NO}_{\mathrm{x}}$, $\mathrm{SO}_{2}$, particulates and formaldehyde. Gas cooking stoves and ovens also release these products directly into the indoor air. Under normal operating conditions, vented gas-fired forced air heaters and water heaters should not release combustion products into the indoor 
air. However flue gas spillage and back drafting can occur with faulty appliances when the room is depressurized by competing exhaust systems and under certain meteorological conditions.

The indoor research studies in various types of buildings were carried out within the research projects. The investigation of carbon dioxides, nitrogen oxides, particles and volatile organic compounds concerning to building materials, furnishing, occupancy and other indoor operation sources were the main subjects of the interest. Present results (Fig.1) confirmed the highest priority of chemicals especially volatile organic compounds which are closely associated with odors and characterize the occurrence of odorants in indoor air. Odors are perhaps the most pressing of all air quality problems. The presence of odors in air may or may not represent a health risk, but no other air pollution problems will provoke such an immediate response. The most risk group of buildings are school buildings (the air quality was under basic hygiene level) and office buildings (the highest level of pollution related to interior materials). The perceived air quality assessment only by indicator of occupant's presence $\left(\mathrm{CO}_{2}\right)$ has shown as insufficient. Objective assessment should be at least extended of TVOC concentrations [4].

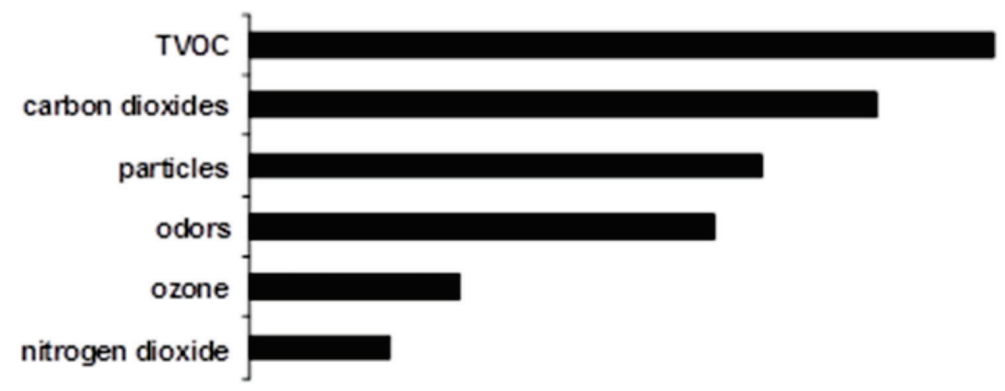

Fig. 1. Indoor air chemicals ranking [4].

Organic compounds originate from a variety of indoor sources and outdoors. Hundreds of organic chemicals occur in indoor air although most are present at very low concentrations. It is generally known that these can be grouped according to their boiling points and one widely used classification, shown in the Table 1, identifies four groups of organic compounds: very volatile organic compounds (VVOC), volatile (VOC), semivolatile (SVOC), and organic compounds associated with particulate matter (POM). Particle-phase organics are dissolved in or adsorbed on particulate matter. They may occur in both the vapour and particle phase depending on their volatility. For example, polyaromatic hydrocarbons (PAHs) consisting of two fused benzene rings (e.g., naphthalene) are found principally in the vapour phase and those consisting of five rings (e.g., benz(a)pyrene) are found predominantly in the particle phase.

A major pollutant in indoor air are volatile organic compounds (VOCs) emitted from materials and building products [5]. Definition by U.S. EPA is: VOC means a hydrocarbon or derivative of hydrocarbon that has a vapor pressure greater than $0.01 \mathrm{kPa}(0.002 \mathrm{psi})$ at a temperature of $20^{\circ} \mathrm{C}$ and pressure of $102.9 \mathrm{kPa}(14.7 \mathrm{psi})$. Excluded compounds are methane, ethane, methylene chloride, 1,1,1-trichloroethane (methyl chloroform), trichlorofluoromethane, dichlorodifluoromethane (CFC-12), chlorodifluoromethane (CFC22), trifluoromethane (FC-23), trichlorotrifluoroethane (CFC-113), dichlorotetrafluoroethane (CFC-114), and chloropentafluoroethane (CFC-115) [6]. Indoor air pollution by VOCs is a particularly variable phenomenon: type and concentration of VOCs may change from one indoor space to another and concentrations may vary between different locations within the same space. 
Table 1. Organic compounds classification.

\begin{tabular}{|c|c|}
\hline Description & Boiling range $\left({ }^{\mathbf{}} \mathbf{C}\right)$ \\
\hline Very volatile organic compounds (VVOC) & $<0$ to $50-100$ \\
\hline Volatile organic compounds (VOC) & $50-100$ to $240-260$ \\
\hline Semi volatile organic compounds (SVOC) & $240-260$ to $380-400$ \\
\hline $\begin{array}{c}\text { Organic compounds associated with particulate } \\
\text { matter or particulate organic mater (POM) }\end{array}$ & 380 \\
\hline
\end{tabular}

Building materials can have a major impact on air quality and can affect occupants, especially sensitive ones including children, the elderly, and patients who are immunecompromised or have respiratory problems. Careful selection of materials along with proper ventilation, operation, and maintenance can improve air quality.

Classification of health effects of indoor air pollution is possible to introduce from comfort point of view. The cause of sick building syndrome remains unknown, although it is likely that there are connections between psychological factors, inadequate ventilation and the level of hygiene in the building. Factors identified as possible causative agents are briefly summarized in Table 2 .

Table 2. Selected indoor pollutants and health effects [7].

\begin{tabular}{|c|c|c|}
\hline Pollutants & Source & Health effects \\
\hline $\mathrm{CO}_{2}$ & Humans & SBS \\
\hline $\mathrm{VOC}_{\mathrm{s}}$ & Interior materials & SBS, acute risk, chronic risk \\
\hline $\mathrm{CO}$ & Combustion & acute risk - respiratory, neurology \\
\hline $\mathrm{NO}_{\mathrm{x}}$ & Combustion & Acute risk - respiratory \\
\hline $\mathrm{O}_{3}$ & Laser printers & Acute risk - rhinitis \\
\hline Particles & Materials & Chronic risk - cancer \\
\hline
\end{tabular}

\section{Volatile organic compounds measurements}

Concentration of total volatile organic compounds (TVOC) expressed as concentration of toluene was measured with ppbRAE 3000 , which is a photoionization detector (PID) with UV lamp. This device has a measuring range of $1 \mathrm{ppb}$ to $10000 \mathrm{ppm}$ and measurement accuracy $\pm 3 \%$. Three-second response time allows real-time monitoring with this instrument. Ultra-fast electronic nose called $z N o s e \AA$, which is based on combination of gas chromatography and surface acoustic wave detector was used for sampling and analysis of individual VOCs. Manufacturer of this device specifies the standard deviation $<2 \%$.

Building materials and interior surfaces release a wide range of other VOCs which have been the subject of increasing. The emission can be a complex mixture of individual compounds, though a few may be dominant. A study of selected building materials identified different chemical species. These VOCs were primarily aliphatic and aromatic hydrocarbons, their oxygen derivatives and terpenes. The compounds with the highest steady-state emission concentrations, in decreasing order, were toluene, m-xylene, terpene, n-butylacetate, n-butanol, n-hexane, p-xylene, ethoxyethylacetate, n-heptane and o-xylene. The complexity of emission has resulted in indoor concentrations often being reported as the total volatile organic compound (TVOC) concentration or release. Table 3 gives examples of rates of TVOC emission for a range of interior building materials. These show that significant differences in emissions exist between products, which mean that if adequate data were available materials could be selected at the planning stage to minimize the VOC release in newly constructed buildings. 
Table 3. TVOC concentrations associated with various floor and wall coverings.

\begin{tabular}{|c|c|}
\hline Typ of materials & Concentrations $\left(\mathrm{mg} / \mathrm{m}^{3}\right)$ \\
\hline wallpaper - vinyl, paper & 1.24 \\
\hline wallpaper - printed paper & 0.87 \\
\hline Hessian & 0.36 \\
\hline Wallpaper-textile & 2.11 \\
\hline Linoleum & 4.95 \\
\hline PVC flooring & 19.12 \\
\hline soft plastic flooring & 3.75 \\
\hline Laminate flooring & 5.27 \\
\hline Wooden flooring & 0.74 \\
\hline Carpeting & 2.89 \\
\hline Cork flooring & 0.56 \\
\hline
\end{tabular}

Many VOCs are present in the indoor environment at concentrations ranging from approximately 2 to $20 \mathrm{mg} / \mathrm{m}^{3}$. Building materials make a significant contribution to indoor concentrations and new homes are likely to have a greater number of compounds exceeding $100 \mathrm{mg} / \mathrm{m}^{3}$. Renovation and painting contribute to significantly higher VOC levels. Concentrations of compounds such as ethyl acetate, 1,1,1-trichloroethane and limonene can exceed $20 \mathrm{mg} / \mathrm{m}^{3}$ during occupant activities, and during residents' absence the concentration of a range of VOCs may decrease by about $50 \%$. Specific cases of elevated concentrations of contaminants due to materials and furnishings being associated with occupant complaints have been described. These include white spirit from injected dampproof courses, naphthalene from products containing coal tar, ethylhexanol from vinyl flooring and formaldehyde from wood-based products.

\section{Perceived indoor discomfort}

In the case of perceived discomfort in public buildings, the questionnaire as subjective assessment tool includes characteristics covering age, gender, type of work and type of work. Questions also ask about users' perceived comfort related with physical factors in the indoor environment covering temperature, indoor air quality, lightning and noise; including users' assessment of productivity in relation to perceived factors. Important part of the questionnaire includes questions related with tested buildings negative factors affected primarily psychical well-being of users. Occupants would then ask about other unknown factors with impact on their well-being, sick building syndrome symptoms and work performance.The SBS symptoms reported after one hour long testing procedure had significantly increased occurrence with decreased ventilation rate. The participants noticed mainly symptoms as dry nose, headache, fatigue, decreasing in reaction speed, inability to concentrate. Several seldom reported symptoms were also noticed. Percentage of individual SBS symptoms occurrence is presented in the Figure 2. Classification of health effects of indoor air quality is possible to introduce from acceptability point of view. The cause of sick building syndrome remains unknown, although it is likely that there are connection between psychological factors, inadequate ventilation and the level of hygiene in the building. Factors identified as possible causative agents are briefly summarized as temperature, humidity, light, noise and odors. 


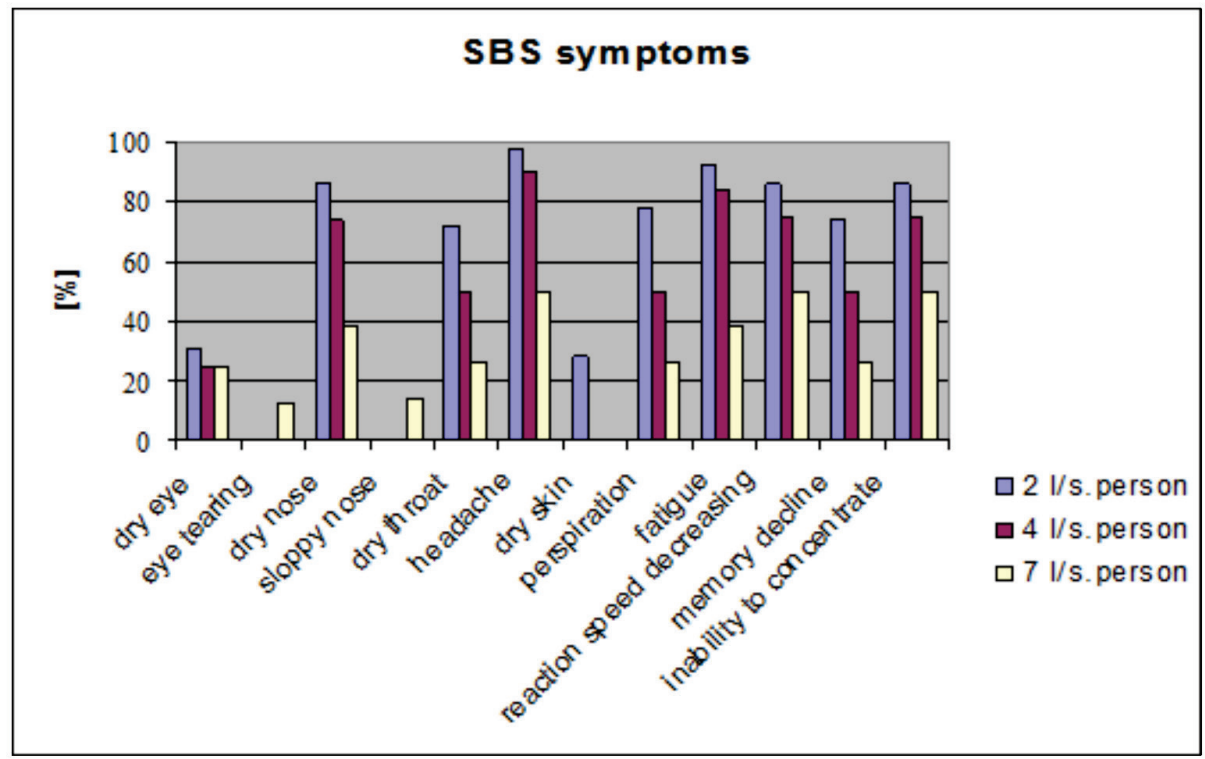

Fig. 2. Percentage of individual SBS symptoms occurrence [8].

\section{Conclusions}

Even all indoor environmental standards are met the users are usually not satisfied and perceived discomfort is occurred in the smart buildings. The most frequently cause of discomfort in smart buildings is overrun of intelligence. There are physical and psychological factors that influenced building users' comfort. Poor indoor air quality is believed to be responsible for a substantial part of the sick building syndrome that has been reported, but the indoor environment is extremely complex and other factors also undoubtedly contribute to the problem. Provided an environmental and economic will within our society will became aware of the real needs of solving the healthy buildings problem - we are able to offer the models and strategies the tools, and criteria, and finally the construction technology and an architectural idiom to design, to build, and to maintain a sustainable buildings on short and long term as well as affordable. A health impact assessment and an environment impact assessment are needed to judge the real quality of a building and particularly indoor design.

The author is grateful to national grant agency for supporting the indoor air sciences research projects.

\section{References}

1. I. Juhasova Senitkova, MATEC Web of Conferences 93, 03001 (2017)

2. I. Senitkova, Material Science Engineering C 36, 6 (2014)

3. I. Senitkova, T.Tomcik, Advanced Science Letters 19, 9 (2013)

4. I. Senitkova, Selected Scientific Papers 2, 35-48, (2007)

5. O.Wilke, O. Jann, D. Brödner, Indoor Air 14, 98-107, (2004)

6. United States Environmental Protection Agency. SIP - NWAPA580

7. I. Senitkova, M. Bucakova, Selected Scientific Papers 3, 45-56 (2008)

8. I. Senitkova, M. Badida, ISEC-7, 1-6 (2013) 